\title{
Morfodiagnose da anatomia foliar e caulinar de Camellia sinensis
} (L.) Kuntze, Theaceae

\author{
Márcia R. Duarte*, Daniele O. Menarim \\ Laboratório de Farmacognosia, Departamento de Farmácia, Universidade Federal do Paraná, Av. Pref. Lothário \\ Meissner 632, 80210-170, Curitiba, PR, Brasil
}

\begin{abstract}
RESUMO: Camellia sinensis é um arbusto ou árvore de pequeno porte, de origem asiática, denominado de chá-da-índia, chá-verde ou chá-preto. Possui atividades antioxidante, antiinflamatória, antimicrobiana e hepatoprotetora. A comercialização dessa espécie é relevante, como droga farmacognóstica e insumo na indústria de bebidas. O presente trabalho trata da caracterização estrutural de folha e caule, de modo a contribuir na morfodiagnose para o controle de qualidade. Amostras do material vegetal foram fixadas, seccionadas e coradas com azul de astra e fucsina básica. Testes microquímicos usuais foram realizados. A folha apresenta estômatos anomocíticos na face abaxial, tricomas tectores unicelulares em ambas as superfícies, mesofilo dorsiventral, drusas de oxalato de cálcio, nervura central biconvexa e pecíolo plano-convexo, ambos percorridos por feixe vascular colateral. O caule, no nível analisado, possui epiderme unisseriada, camada subepidérmica de células colabadas, bainha esclerenquimática, estrato de células com paredes espessadas em $U$, organização vascular colateral e medula com células parenquimáticas e esclerenquimáticas. Esclereídes são encontradas na folha e no caule.
\end{abstract}

Unitermos: Camellia sinensis, chá-da-índia, chá-preto, chá-verde, controle de qualidade, esclereíde.

\begin{abstract}
Leaf and stem anatomical morpho-diagnosis of Camellia sinensis (L.) Kuntze, Theaceae". Camellia sinensis is a shrub or small tree, of Asian origin and commonly called Chinese tea, green tea or black tea. This species has antioxidant, anti-inflammatory, antimicrobial and hepatic protective activities. Its trade is relevant, either as pharmacognostic drug or raw material in food industry. This work has dealt with the structural diagnosis of the leaf and stem, in order to contribute to its quality control. Samples of the botanical material were fixed, sectioned and stained with astra blue and basic fuchsine. Microchemical tests were also conducted. The leaf has anomocytic stomata on the abaxial side, unicellular non-glandular trichomes on both surfaces, dorsiventral mesophyll, calcium oxalate druses, biconvex midrib and plain-convex petiole, both traversed by a collateral vascular bundle. The stem, on the level analysed, shows uniseriate epidermis, sub-epidermal layer of dehydrated cells, sclerenchymatic sheath, strand of cells with U-thickened walls, collateral vascular organization and pith consisting of parenchymatic and sclerenchymatic cells. Sclereids are found in the leaf and stem.
\end{abstract}

Keywords: Camellia sinensis, black tea, Chinese tea, green tea, quality control, sclereid.

\section{INTRODUÇÃO}

Camellia sinensis (L.) Kuntze (Figuras 1, 2) é um arbusto ou árvore de pequeno porte, de origem asiática, pertencente à família Theaceae. Apresenta folhas simples, alternas, inteiras, com margem serreada e textura coriácea (Lorenzi; Matos, 2002). É designado genericamente como chá-da-índia ou como chá-verde, oolong e chá-preto, em referência ao produto resultante do preparo diferencial das folhas. Folhas recém coletadas e imediatamente estabilizadas caracterizam o chá-verde e, quando submetidas à fermentação, rápida ou prolongada, constituem o tipo oolong e o chá-preto, respectivamente (Ody, 1993; Weisburger, 1997; Kuhn; Winston, 2000). O processo fermentativo favorece a oxidação enzimática dos polifenóis presentes, conferindo menor adstringência

*E-mail:marciard@ufpr.br,Tel.+55-41-33604064 e coloração mais intensa ao material vegetal (Simonetti, 1990).

Diferentes grupos de compostos químicos têm sido investigados em C. sinensis, tais como alcalóides púricos (Ito et al., 1997; Liang et al., 2001) e polifenóis (Liang et al., 2001; Punyasiri et al., 2004; Peterson et al., 2005). Há registro que esta planta é utilizada como medicinal no município de Campos de Goytacazes - Rio de Janeiro (Pereira et al., 2004). Numerosos ensaios farmacológicos têm comprovado atividades antioxidante (Fiorini et al., 2005; Kalra et al., 2005), antiinflamatória (Nag-Chaudhuri et al., 2005), hepatoprotetora (Fiorini et al., 2005), antimicrobiana (Yam et al., 1997; Turchetti et al., 2005), hipoglicemiante (Barbosa-Filho et al., 2005), inibidora da enzima conversora de angiotensina (Barbosa-Filho et al., 2006) e antimutagênica (Santhosh 
et al., 2005). Em razão desses efeitos, estudos procuram avaliar a eficiência terapêutica da droga e dos metabólitos secundários para prevenção de câncer (Lambert; Yang, 2003; Halder et al., 2005) e osteoporose (Das et al., 2004), tratamento de diabetes (Gomes et al., 1995; Funke; Melzig, 2006), úlcera (Maity et al., 1995) e Alzheimer (Okello et al., 2004).

Embora a comercialização dessa espécie vegetal seja relevante, tanto como droga com fins farmacognósticos quanto insumo na indústria de bebidas, poucos trabalhos tratam de caracteres morfoanatômicos de folha e caule, que possam ser aplicáveis ao controle de qualidade. Quando esses aspectos são mencionados, se referem exclusivamente à folha, cuja interpretação na prática é dificultada ao estar finamente fragmentada e acompanhada de material caulinar (McGuffin et al., 1997; Kuhn; Winston, 2000). Na composição de diferentes tipos de chá-da-índia, folhas jovens são coletadas juntamente com ramos apicais. Do mesmo modo que a morfoanatomia de algumas plantas de interesse medicinal foi investigada em trabalhos anteriores (Duarte; Debur, 2003; Souza et al., 2003; Duarte; Hayashi, 2005; Duarte; Wolf, 2005; Farago et al., 2005; Larrosa; Duarte, 2005; Budel et al., 2006; Toledo et al., 2006), a presente investigação tem por objetivo abordar os caracteres anatômicos foliar e caulinar de $C$. sinensis, de modo a contribuir na morfodiagnose dessa espécie.

\section{MATERIAL E MÉTODOS}

Amostras do material vegetal foram coletadas de plantas cultivadas em Araucária, município da região metropolitana de Curitiba, PR, cujas coordenadas aproximadas são $25^{\circ} 26^{\prime}$ S e $49^{\circ} 14^{\prime}$ W, em março de 2005. A identificação taxonômica foi feita por comparação com a exsicata depositada no Herbário do Museu Botânico Municipal de Curitiba, PR, sob número MBM 251476.

Fragmentos de caules obtidos a 5-20 cm do ápice caulinar e folhas coletadas a partir do quarto nó foram fixados em FAA 70 (Johansen, 1940). Após uma semana, o fixador foi substituído por etanol a 70\% (Berlyn; Miksche, 1976) e o material foi seccionado à mão livre, nos sentidos transversal e longitudinal. Os cortes foram corados com azul de astra e fucsina básica (Roeser, 1972) ou submetidos a testes microquímicos. Estes foram realizados com as soluções de lugol (Berlyn; Miksche, 1976) para amido, floroglucina clorídrica (Sass, 1951) para elementos lignificados, Sudan IV (Foster, 1949) para substâncias lipofílicas, cloreto férrico (Johansen, 1940) para compostos fenólicos, e ácido sulfúrico (Oliveira; Akisue, 1989) para cristais de oxalato de cálcio. Fotomicrografias foram obtidas no microscópio fotônico Olympus BX40 equipado com a unidade de controle PM20.

\section{RESULTADOS}

\section{Morfodiagnose foliar}

No limbo, as células epidérmicas apresentam contorno ondulado e visíveis campos primários de pontoação, em vista frontal (Figuras 3, 4). A epiderme constitui-se de uma única camada de células, cujas paredes anticlinais e periclinais são comparativamente espessadas (Figura 6). Estômatos anomocíticos localizamse exclusivamente na face abaxial (Figura 4) e inseremse no mesmo nível das células circunvizinhas. Tricomas tectores unicelulares (Figura 5), de paredes espessadas e impregnadas de lignina, com ápice agudo e circundados na base por células epidérmicas em roseta, estão presentes em ambas as superfícies. O mesofilo é dorsiventral, sendo formado de um ou dois estratos de parênquima paliçádico e diversas camadas de parênquima esponjoso, que corresponde a $60 \%$ do clorênquima (Figura 6). Feixes vasculares colaterais, envoltos por bainha parenquimática, distribuem-se em meio ao mesofilo (Figura 6). Os feixes de médio porte apresentam calotas esclerenquimáticas apostas ao xilema e ao floema.

A nervura central tem secção biconvexa (Figura 7) e a epiderme possui as mesmas características previamente descritas, sendo revestida por cutícula relativamente mais espessa e que se projeta entre as paredes anticlinais, estabelecendo flanges cuticulares. Subjacente ao sistema de revestimento, nota-se o colênquima anelar, formado por cerca de quatro camadas junto à face adaxial e de três no lado oposto. Mergulhado no parênquima fundamental, encontra-se um feixe vascular colateral, em arco aberto, com calotas de fibras perivasculares apostas ao xilema e floema, que podem se unir e constituir bainha esclerenquimática (Figuras $7,8)$. Ocasionalmente, esse feixe é acompanhado de um ou dois feixes menores. O xilema é todo lignificado e os elementos traqueais enfileiram-se, sendo separados por raios parenquimáticos que prosseguem em direção ao floema (Figura 8).

Idioblastos contendo drusas de oxalato de cálcio e esclereídes localizam-se no mesofilo e freqüentemente nas proximidades do feixe vascular da nervura central (Figura 8). As esclereídes possuem paredes espessadas e lignificadas, com pontoações nítidas e pequenos prolongamentos que lhes conferem formato irregular.

O pecíolo é plano junto à face adaxial e convexo na superfície abaxial, e tem duas pequenas projeções laterais na região distal. Revela organização interna semelhante à nervura central, mostrando feixe vascular colateral, tendendo à disposição em arco fechado, circundado por bainha esclerenquimática em processo de lignificação e bainha amilífera.

\section{Morfodiagnose caulinar}

O caule, no nível analisado, apresenta secção circular (Figura 9) e é revestido por epiderme unisseriada. Notam-se tricomas tectores unicelulares 

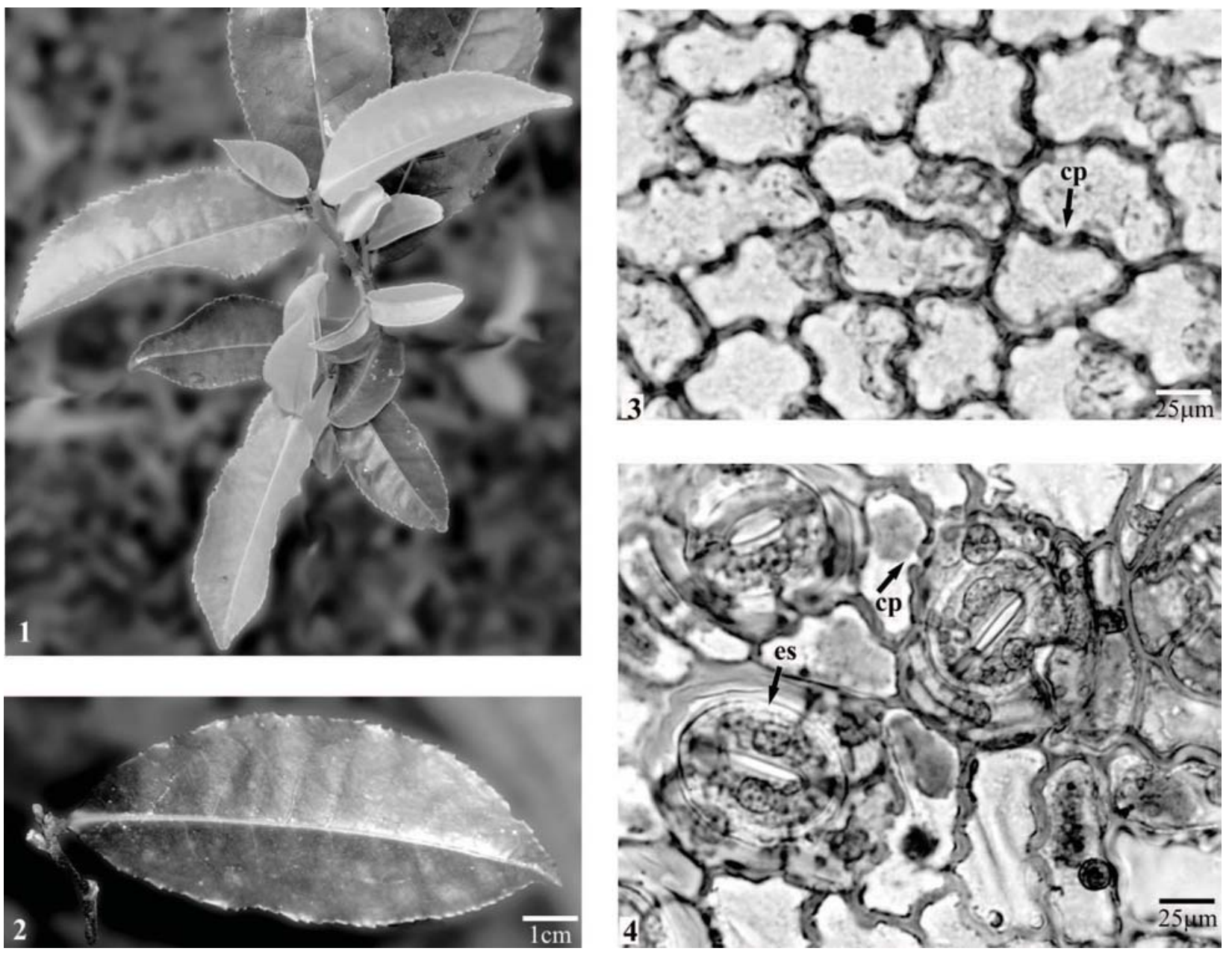

Figuras 1-4. Camellia sinensis (L.) Kuntze, Theaceae: 1. ramo vegetativo apical; 2. detalhe da folha; 3 e 4 . vista frontal da epiderme foliar, faces adaxial e abaxial, respectivamente. cp - campos primários de pontoação, es - estômato.

e duas ou três camadas subepidérmicas de células com paredes colabadas (Figura 10). Uma bainha contínua de células esclerenquimáticas, formada de cerca de quatro camadas, e um estrato de células de paredes espessadas em U, impregnadas de substâncias lipofílicas e de lúmen poligonal em secção transversal, circundam o sistema vascular. Este tem organização colateral e zona cambial evidente (Figura 10). O floema e o xilema se dispõem como cilindros contínuos e são percorridos por raios parenquimáticos estreitos, lignificados na região xilemática. Esparsas fibras encontram-se no floema. A medula corresponde a aproximadamente $40 \%$ do volume caulinar (Figura 9) e consiste de células parenquimáticas relativamente grandes e contendo amiloplastos, células esclerenquimáticas menores e esclereídes (Figura 11).

\section{DISCUSSÃO}

Na espécie estudada, os caracteres da epiderme foliar são concordantes com a descrição de Perrot (1943/4) e Younkgen (1950), quanto à presença de estômatos anomocíticos na face abaxial e de tricomas tectores unicelulares. No entanto, para esses autores as células epidérmicas possuem contorno poligonal, em vista frontal. De acordo com Gilg et al. (1942), as características anatômicas variam com a idade das folhas de C. sinensis, podendo o contorno ser poligonal a ondulado.

Diferentemente ainda do observado, Mukherjee et al. (2000) e Tsay et al. (2002) relatam a ocorrência de tricomas exclusivamente na superfície abaxial na espécie. Para Gilg et al. (1942), folhas jovens possuem esses anexos epidérmicos na face inferior e estes progressivamente se destacam, tornando as folhas adultas glabras. Todavia, Metcalfe e Chalk (1988) mencionam que a freqüência e o tamanho dos tricomas podem variar em razão das condições ambientais, sendo a classificação do tipo de maior importância taxonômica. Com relação a espécies produtoras de polifenóis, na opinião de Hollósy (2002), os tricomas podem conter flavonóides, compostos fotoestáveis que interceptam a radiação ultravioleta e assumem o papel de uma barreira protetora contra os 
efeitos danosos dos raios UV-B, impedindo-os de alcançar o mesofilo e afetar a fotossíntese.

Na família Theaceae, a folha é geralmente dorsiventral, onde o parênquima esponjoso ocupa praticamente dois terços do mesofilo, e mostra idioblastos esclerenquimáticos e cristais de oxalato de cálcio (Metcalfe; Chalk, 1950). Esses aspectos estão presentes em C. sinensis (Gilg et al., 1942; Perrot, 1943/4; Younkgen, 1950) e têm correspondência com o verificado neste estudo. Embora, Gilg et al. (1942) e Younkgen (1950) façam referência a células pétreas com numerosos braços na folha e levando-se em conta que células pétreas são consideradas esclereídes praticamente isodiamétricas (Fahn, 1990), esses elementos devem ser designados apropriadamente como esclereídes. Estas fazem parte do sistema de sustentação e são mencionadas por diferentes autores como relevantes marcadores anatômicos da espécie, juntamente com os tricomas tectores (Gilg et al., 1942; Perrot, 1943/4; Younkgen, 1950; Loggia, 1993). De um modo geral, o esclerênquima, a exemplo das esclereídes, das calotas apostas aos feixes vasculares que percorrem o mesofilo e da bainha que circunda o feixe vascular da nervura central de C. sinensis, determina maior resistência mecânica ao órgão foliar, o que dificulta a predação por herbívoros (Roth-Nebelsick et al., 2001).

Cristais de oxalato de cálcio ocorrem freqüentemente na forma de prismas ou drusas nas Theaceae (Metcalfe; Chalk, 1950), estando o segundo tipo presente nas folhas da espécie investigada (Gilg et al., 1942; Perrot 1943/4; Metcalfe; Chalk, 1950; Younkgen, 1950). Várias funções têm-lhes sido atribuídas, por exemplo, como as relacionadas com a defesa à herbivoria, a concentração e difusão luminosa, a regulação metabólica de cálcio e a detoxificação de ácido oxálico ou metais pesados (Nakata, 2003).

Com referência aos aspectos caulinares para a família, o caule jovem comumente tem secção circular e possui colênquima no córtex, endoderme indistinguível, periciclo esclerificado, cilindros contínuos de floema e xilemapercorridos por raios estreitos e medula heterogênea com células esclerenquimáticas e parenquimáticas, além de esclereídes (Metcalfe; Chalk, 1950). A espécie do presente estudo tem caracteres compatíveis aos da família, bem como apresenta um estrato de células com paredes
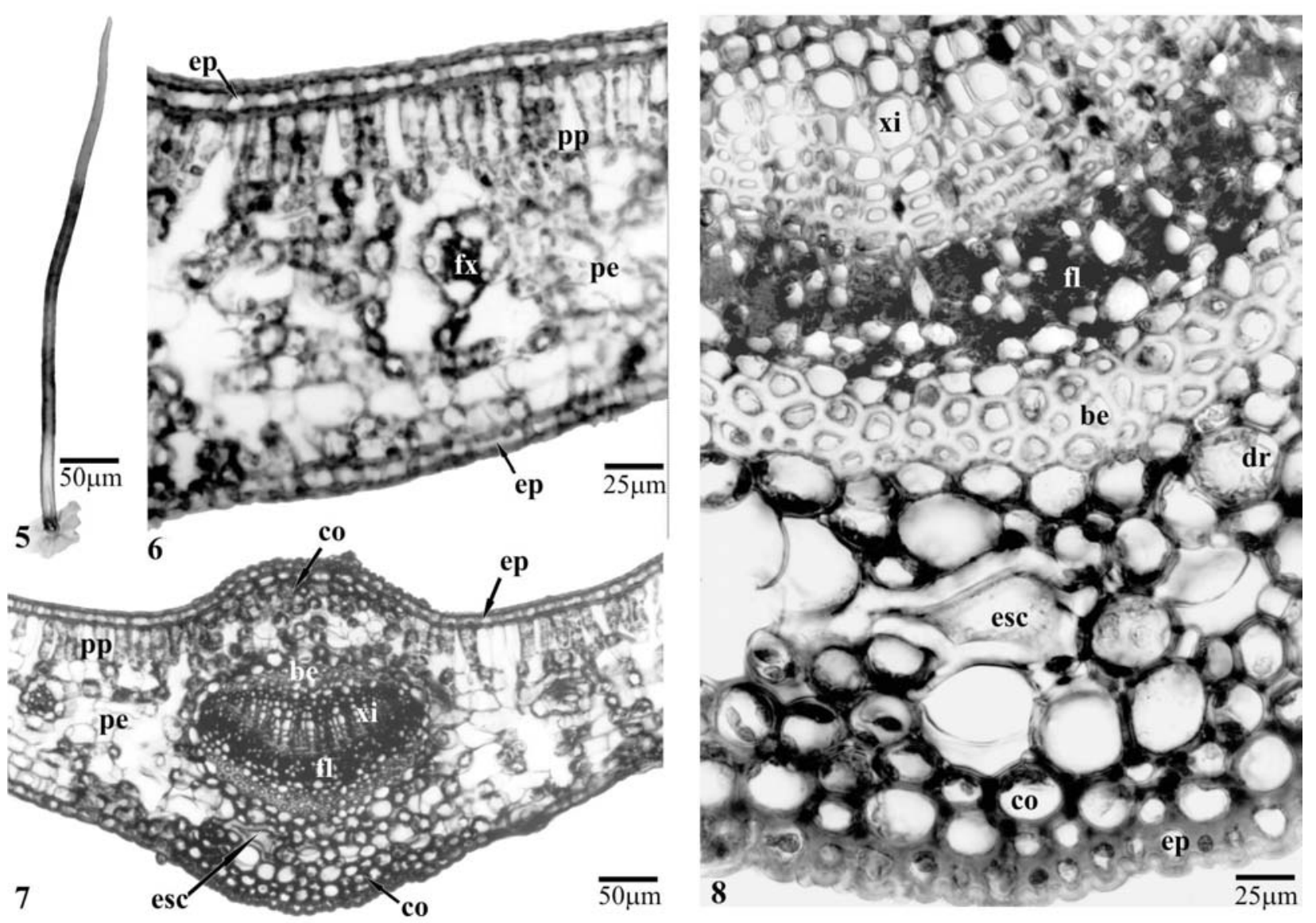

Figuras 5-8. Camellia sinensis - folha: 5. tricoma tector; 6. secção transversal do limbo, mostrando mesofilo dorsiventral; 7. secção transversal da nervura central biconvexa; 8 . detalhe da nervura central, destacando feixe vascular colateral e esclereíde. be - bainha esclerenquimática, co - colênquima, $\mathrm{dr}$ - drusa, ep - epiderme, esc - esclereíde, fl - floema, $\mathrm{fx}$ - feixe vascular, pe - parênquima esponjoso, $\mathrm{pp}$ - parênquima paliçádico. 

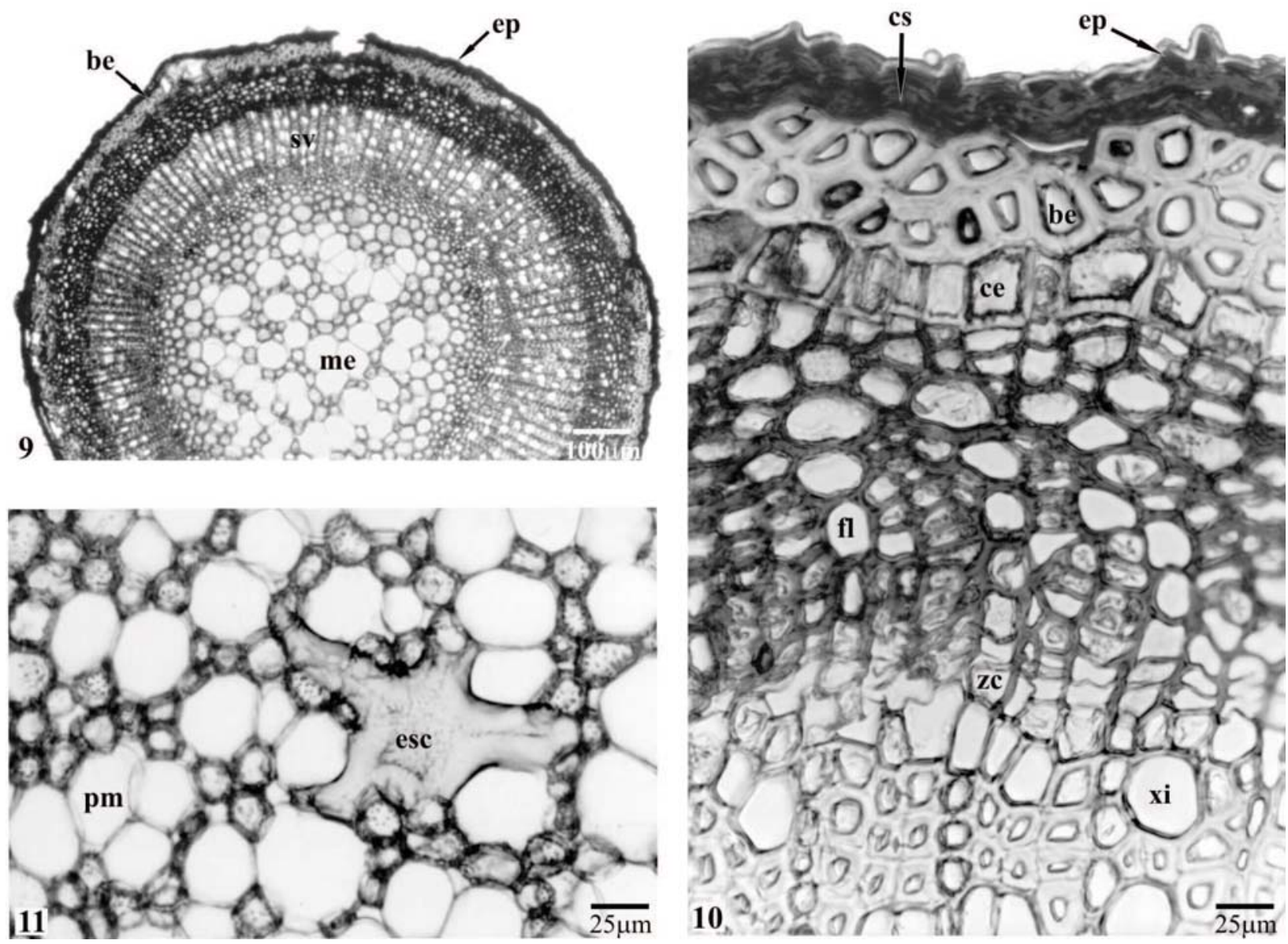

Figuras 9-11. Camellia sinensis - caule: 9. organização caulinar; 10. detalhe da figura anterior, indicando camada subepidérmica de células de paredes colabadas, bainha esclerenquimática, células com paredes espessadas em U e zona cambial; 11. esclereíde na medula. be - bainha esclerenquimática, ce - células espessadas em U, cs - camada subepidérmica, ep - epiderme, esc - esclereíde, fl - floema, me - medula, pm - parênquima medular, sv - sistema vascular, xi - xilema, zc - zona cambial.

espessadas em U subjacente à bainha esclerenquimática. No gênero Camellia, o córtex é reduzido e o felogênio se instala no periciclo, originando súber com células de paredes espessadas tipicamente em U (Metcalfe; Chalk, 1950). Pela organização estrutural da espécie analisada, a camada subepidérmica tem correspondência com o colênquima, a bainha esclerenquimática com o periciclo, que é completamente esclerificado na família, e as células de paredes espessadas em U, que apresentam compostos lipofílicos compatíveis com impregnação de suberina, correspondem ao súber. Camellia cuspidata (Kochs) Wright ex Hort. revela anatomia caulinar semelhante (Metcalfe; Chalk, 1950).

\section{CONCLUSÕES}

A caracterização da organização estrutural de folha e caule de C. sinensis contribui para a morfodiagnose da espécie. Caracteres anatômicos, como estômatos anomocíticos exclusivamente na face abaxial, tricomas tectores unicelulares em ambas as superfícies, mesofilo dorsiventral, feixes vasculares colaterais, drusas de oxalato de cálcio e esclereídes, permitem a identificação da folha que constitui a droga vegetal. Tratando-se de insumo para a indústria de bebidas, somam-se às características foliares as caulinares, a saber, bainha esclerenquimática, estrato de células de paredes espessadas em U, arranjo vascular colateral e medula heterogênea.

\section{AGRADECIMENTOS}

Os autores agradecem à empresa Agro Chá Boa Vista Ltda. pelo fornecimento dos exemplares vegetais e aos taxonomistas do Museu Botânico Municipal de Curitiba pela confirmação da identidade da espécie.

\section{REFERÊNCIAS}

Barbosa-Filho JM, Vasconcelos THC, Alencar AA, Batista 
LM, Oliveira RAG, Guedes DN, Falcão HS, Moura MD, Diniz MFFM, Modesto-Filho J 2005. Plants and their active constituents from South, Central, and North America with hypoglycemic activity. Rev Bras Farmacogn 15: 392-413.

Barbosa-Filho JM, Martins VKM, Rabelo LA, Moura MD, Silva MS, Cunha EVL, Souza MFV, Almeida RN, Medeiros IA 2006. Natural products inhibitors of the angiotensin converting enzyme (ACE). A review between 19802000. Rev Bras Farmacogn 16: 421-446.

Berlyn GP, Miksche JP 1976. Botanical microtechnique and cytochemistry. Ames: Iowa State University.

Budel JM, Duarte MR, Farago PV, Takeda IJM 2006. Caracteres anatômicos de folha e caule de Calea unifl ora Less., Asteraceae. Rev Bras Farmacogn 16: 53-60.

Das AS, Mukherjee M, Mitra C 2004. Evidence for a prospective anti-osteoporosis effect of black tea (Camellia sinensis) extract in a bilaterally ovariectomized rat model. Asia Pac J Clin Nutr 13: 210-216.

Duarte MR, Debur MC 2003. Caracteres morfo-anatômicos de folhas e caule de Bauhinia microstachaya (Raddi) J.F. Macbr. (Fabaceae). Rev Bras Farmacogn 13: 7-15.

Duarte MR, Hayashi SS 2005. Estudo anatômico de folha e caule de Pereskia aculeata Mill. (Cactaceae). Rev Bras Farmacogn 15: 103-109.

Duarte MR, Wolf S 2005. Anatomical characters of the phyllode and stem of Acacia podalyriifolia A. Cunn. ex G. Don (Fabaceae). Rev Bras Farmacogn 15: 71-76.

Fahn A. 1990. Plant anatomy. $4^{\text {th }}$ ed. Oxford: Pergamon Press.

Farago PV, Budel JM, Duarte MR, Nakashima T 2005. Análise morfoanatômica de folhas de Ocotea puberula (Rich.) Nees, Lauraceae. Rev Bras Farmacogn 15: 250-255.

Fiorini RN, Donovan JL, Rodwell D, Evans Z, Cheng G, May HD, Milliken CE, Markowitz JS, Campbell C, Haines JK, Schmidt MG, Chavin KD 2005. Short-term administration of (-)-epigallocatechin gallate reduces hepatic steatosis and protects against warm hepatic ischemia/reperfusion injury in steatotic mice. Liver Transpl 11: 298-308.

Foster AS 1949. Practical plant anatomy. $2^{\text {nd }}$ ed. Princeton: D.Van Nostrand.

Funke I, Melzig MF 2006. Traditionally used plants in diabetes therapy - phytotherapeutics as inhibitors of $\alpha$-amylase activity. Rev Bras Farmacogn 16: 1-5.

Gilg E, Brandt W, Schürhoff PN 1942. Farmacognosia-materia farmacéutica vegetal y animal. Barcelona: Labor.

Gomes A, Vedasiromoni JR, Das M, Sharma RM, Ganguly DK 1995. Anti-hyperglycemic effect of black tea (Camellia sinensis) in rat. J Ethnopharmacol 45: 223-226.

Halder A, Raychowdhury R, Ghosh A, De M 2005. Black tea (Camellia sinensis) as a chemopreventive agent in oral precancerous lesions. Environ Pathol Toxicol Oncol 24: 141-144.

Hollósy F 2002. Effects of ultraviolet radiation on plant cells. Micron 33: 179-197.

Ito E, Crozier A, Ashihara H 1997. Theophylline metabolism in higher plants. Biochim Biophys Acta 1336: 323-330.

Johansen DA 1940. Plant microtechnique. New York: McGrawHill Book.

Kalra N, Prasad S, Shukla Y 2005. Antioxidant potential of black tea against 7,12-dimethylbenz(a)anthraceneinduced oxidative stress in Swiss albino mice. $J$ Environ Pathol Toxicol Oncol 24: 105-114.
Kuhn MA, Winston D 2000. Herbal therapy and supplements. Philadelphia: Lippincott.

Lambert JD, Yang CS 2003. Cancer chemopreventive activity and bioavailability of tea and tea polyphenols. Mutat Res 523/524: 201-208.

Larrosa CRR, Duarte MR 2005. Contribuição ao estudo anatômico do caule de Himatanthus sucuuba (Spruce ex Müll. Arg.) Woodson, Apocynaceae. Rev Bras Farmacogn 15: 110-114.

Liang Y, Ma W, Lu J, Wu Y 2001. Comparison of chemical compositions of Ilex latifolia Thumb and Camellia sinensis L. Food Chem 75: 339-343.

Loggia R 1993. Piante officinali per infusi e tisane. Milano: Medico Farmaceutica.

Lorenzi H, Matos FJA 2002. Plantas medicinais do Brasil: nativas e exóticas. Nova Odessa: Plantarum.

Maity S, Vedasiromoni JR, Ganguly DK 1995. Anti-ulcer effect of the hot water extract of black tea (Camellia sinensis). J Ethnopharmacol 46: 167-174.

McGuffin M, Hobbs C, Upton R, Goldberg A 1997. Botanical safety handbook. Boca Raton: CRC Press.

Metcalfe CR, Chalk L 1950. Anatomy of the dicotyledons: leaves, stem, and woods in relation to taxonomy with notes on economic uses. Oxford: Clarendon Press. v. 1

Metcalfe CR, Chalk L 1988. Anatomy of the dicotyledons. $2^{\text {nd }}$ ed. Oxford: Clarendon Press.

Mukherjee KK, Roy M, Saha PK, Ganguly SN 2000. Surface morphology of tea (Camellia sinensis L.) leaves. Phytomorphol 50: 125-131.

Nag-Chaudhuri AK, Karmakar S, Roy D, Pal S, Pal M, Sen T 2005. Anti-inflammatory activity of Indian black tea (Sikkim variety). Pharmacol Res 51: 169-175.

Nakata PA 2003. Advances in our understanding of calcium oxalate crystal formation and function in plants. Plant Sci 164: 901-909.

Ody P 1993. Las plantas medicinales. Buenos Aires: Javier Vergara.

Okello EJ, Savelev SU, Perry EK 2004. In vitro anti-betasecretase and dual anti-cholinesterase activities of Camellia sinensis L. (tea) relevant to treatment of dementia. Phytother Res 18: 624-627.

Oliveira F, Akisue G 1989. Fundamentos de farmacobotânica. Rio de Janeiro: Atheneu.

Pereira RC, Oliveira MTR, Lemos GCS 2004. Plantas utilizadas como medicinais no município de Campos de Goytacazes - RJ. Rev Bras Farmacogn 14 (Supl. 1): 37-40.

Perrot E 1943/4. Matières premières usuelles du règne vegetal. Paris: Masson. v.1.

Peterson J, Dwyer J, Bhagwat S, Haytowitz D, Holden J, Eldridge AL, Beecher G, Aladesanmi J 2005. Major flavonoids in dry tea. J Food Comp Anal 18: 487501.

Punyasiri PA, Abeysinghe IS, Kumar V, Treutter D, Duy D, Gosch C, Martens S, Forkmann G, Fischer TC 2004. Flavonoid biosynthesis in the tea plant Camellia sinensis: properties of enzymes of the prominent epicatechin and catechin pathways. Arch Biochem Biophys 431: 22-30.

Roeser KR 1972. Die Nadel der Schwarzkiefer-Massenprodukt und Kunstwerk der Natur. Mikrokosmos 61: 33-36.

Roth-Nebelsick A, Uhl D, Mosbrugger V, Kerp H 2001. 
Evolution and function of leaf venation architecture: a review. Ann Bot 87: 553-566.

Santhosh KT, Swarnam J, Ramadasan K2005. Potent suppressive effect of green tea polyphenols on tobacco-induced mutagenicity. Phytomedicine 12: 216-220.

Sass JE 1951. Botanical microtechnique. $2^{\text {nd }}$ ed. Ames: Iowa State College.

Simonetti G 1990. Guide to herbs and spices. New York: Fireside.

Souza WM, Santos CA, Duarte MR, Bardal D 2003. Morfoanatomia das folhas de nespereira - Eriobotrya japonica Lindl., Rosaceae. Rev Bras Farmacogn 13: 41-49.

Toledo ACO, Duarte MR, Nakashima T 2006. Caracterização morfoanatômica de raiz e rizoma de Symphytum officinale L. (Boraginaceae). Rev Bras Farmacogn 16: 185-191.

Tsay JS, Chen IZ, Chang WC 2002. Observations on surface morphology of leaves in flush of tea (Camellia sinensis) and studies on the pathway of water loss during Paochung tea withering process. J Agric Assoc China 3: 355-375.

Turchetti B, Pinelli P, Buzzini P, Romani A, Heimler D, Franconi F, Martini A 2005. In vitro antimycotic activity of some plant extracts towards yeast and yeast-like strains. Phytother Res 19: 44-49.

Weisburger JH 1997. Tea and health: a historical perspective. Cancer Lett 114: 315-317.

Yam TS, Shah S, Hamilton-Miller JMT 1997. Microbiological activity of whole and fractioned crude extracts of tea (Camellia sinensis), and of tea components. FEMS Microbiol Lett 152: 169-174.

Younkgen HW 1950. Textbook of pharmacognosy. $6^{\text {th }} \mathrm{ed}$. New York: McGraw-Hill Book. 